\title{
A Angústia da Influência
}

Política, Cultura e Ciêncianas relações da Alemanha com a Europa do Sul, 1933-1945

\section{Passagem}

\section{Estudos em Ciências Culturais} Studies in Cultural Sciences Kulturwissenschaftliche Studien

Ed. Marília dos Santos Lopes \& Peter Hanenberg 
A Angústia da Influência 


\section{PASSAGEM \\ ESTUDOS EM CIÊNCIAS CULTURAIS \\ STUDIES IN CULTURAL SCIENCES \\ KULTURWISSENSCHAFTLICHE STUDIEN}

Herausgegeben von

Peter Hanenberg und Marilia Dos Santos Lopes

\section{BAND 7}

Zu Qualitätssicherung und Peer Review der vorliegenden Publikation

Die Qualität der in dieser Reihe erscheinenden Arbeiten wird vor der Publikation durch beide Herausgeber der Reihe sowie externe Gutachter geprüft.
Notes on the quality assurance and peer review of this publication

Prior to publication, the quality of the work published in this series is reviewed by both editors of the series as well as by external referees. 
Fernando Clara / Cláudia Ninhos (eds.)

\section{A Angústia da Influência}

Política, Cultura e Ciência nas relações da Alemanha com a Europa do Sul, 1933-1945 


\section{Bibliographic Information published by the Deutsche}

\section{Nationalbibliothek}

The Deutsche Nationalbibliothek lists this publication in the Deutsche Nationalbibliografie; detailed bibliographic data is available in the internet at http://dnb.d-nb.de.

Cover Design:

(C) Olaf Gloeckler, Atelier Platen, Friedberg

Printed with the support of the Fundação para a Ciência e Tecnologia (PDTC/HIS-HCT/111330/2009).

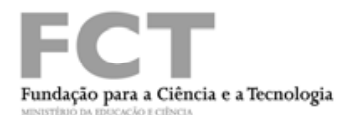

ISSN 1861-583X

ISBN 978-3-631-65429-3 (Print)

E-ISBN 978-3-653-04577-2 (E-Book)

DOI 10.3726/978-3-653-04577-2

(C) Peter Lang GmbH

Internationaler Verlag der Wissenschaften

Frankfurt am Main 2014

All rights reserved.

Peter Lang Edition is an Imprint of Peter Lang GmbH.

Peter Lang - Frankfurt am Main · Bern · Bruxelles · New York ·

Oxford $\cdot$ Warszawa $\cdot$ Wien

All parts of this publication are protected by copyright. Any utilisation outside the strict limits of the copyright law, without the permission of the publisher, is forbidden and liable to prosecution. This applies in particular to reproductions, translations, microfilming, and storage and processing in electronic retrieval systems.

This publication has been peer reviewed.

www.peterlang.com 


\section{passagem \\ Estudos em Ciências Culturais \\ Studies in Cultural Sciences / Kulturwissenschaftliche Studien}

Ed. Marília dos Santos Lopes \& Peter Hanenberg

Band 1 Adriana Alves de Paula Martins: A construção da memória da nação em José Saramago e Gore Vidal. 2006.

Band 2 Fernando Clara: Mundos de Palavras. Viagem, História, Ciência, Literatura: Portugal no Espaço de Lingua Alemã (1770-1810). 2007.

Band 3 Ana Margarida Abrantes: Meaning and Mind. A Cognitive Approach to Peter Weiss' Prose Work. 2010.

Band 4 Peter Hanenberg / Isabel Capeloa Gil/Filomena Viana Guarda/Fernando Clara (Hrsg.): Kulturbau. Aufräumen, Ausräumen, Einräumen. 2010.

Band 5 Ana Margarida Abrantes / Peter Hanenberg (eds.): Cognition and Culture. An Interdisciplinary Dialogue. 2011.

Band 6 Gerald Bär / Howard Gaskill (eds.): Ossian and National Epic. 2012.

Band 7 Fernando Clara / Cláudia Ninhos (eds.): A Angústia da Influência. Política, Cultura e Ciência nas relações da Alemanha com a Europa do Sul, 1933-1945. 2014.

www.peterlang.com 


\section{Índice}

A Alemanha e a Europa do Sul, 1933-1945:

relações influentes, angústias, ansiedades

Fernando Clara / Cláudia Ninhos

Os limites do fascismo transnacional: falangismo, nacional-socialismo e a influência do III Reich em Espanha (1931-1945)..... 13

Xosé M. Núñez Seixas

Itália fascista e política de potência. A exportação da «ideia» fascista no Estado Novo português (1933-1943)

Mario Ivani

À procura de uma «Aliança Espiritual» com a Alemanha.

Do Ultimato Britânico à ascensão do Nacional-Socialismo

Cláudia Ninhos

A Alemanha e a Europeização da Espanha.

Do «Desastre Colonial de 1898» à Segunda Guerra Mundial:

Os Bolseiros da Junta para la Ampliación de Estudios.

Marició Janué i Miret

A «questão da raça», as redes internacionais do Instituto Ibero-Americano de Berlim e as suas relações com Portugal (1933-1945)

Fernando Clara

A receção da eugenia alemã em Portugal, 1933-1945

António Fernando Cascais

Ayres de Azevedo: um eugenista português na Alemanha Nazi

José Pedro Castanheira 
Espaços modernos.

Governamentalidade em Lisboa e em Frankfurt/Main 209

Jorge Freitas Branco

Circulação Teórico-Prática entre o III Reich e o Estado Novo:

Hermann Distel e a Arquitectura Hospitalar....

Ana Mehnert Pascoal

A arqueologia alemã em Portugal e em Espanha na primeira

metade de novecentos: uma ciência, um paradigma,

duas realidades (um primeiro esboço)

Ana Cristina Martins

A tecnologia alemã nos Açores entre as duas guerras mundiais

261

Sérgio Rezendes

Expectativas Goradas: rearmamento e auto-suficiência

industrial no Portugal de entre-guerras

Rui Aballe Vieira

Autores

Índice Onomástico 